\title{
Research on the Competence of Opinion Leaders of Electronic Products Based on DANP
}

\author{
Shuai Zhang ${ }^{1, a^{*}}$, Yuantao Huang ${ }^{2, b}$ \\ ${ }^{1}$ School of Economics \& Management, Harbin Institute of Technology Weihai, China \\ ${ }^{2}$ School of Economics \& Management, Harbin Institute of Technology Weihai, China
}

\begin{abstract}
In order to help enterprises to identify the opinion leaders of electronic products, reduce the cost of buyers and sellers satisfied with the deal, this article from the perspective of victory force elements, opinion leader of electronic products, which can identify the key elements to build the evaluation index system of electronic products of opinion leaders, according to the DEMATEL-Basd Analytic Network Process (DANP) method for empirical research. The results show that there is a mutual influence relationship between the competency factors of opinion leaders of electronic products. Among them, activity is the most important competency factor, and centrality has the greatest influence on other competency factors. Based on this study, management suggestions are put forward for marketers.
\end{abstract}

\section{INTRODUCTION}

The Internet is open, virtual and interactive, which makes the quality of information on the network uneven, the information density is low, and the human communication generally exists weak connection. China's electronic products market has stepped into the mature period, electronic products upgrade fast, innovation ability is constantly enhanced, the competition is more and more fierce, severe market competition for enterprises put forward higher requirements. Opinion leaders can help consumers quickly get the electronic product information they need, help information producers and marketers quickly establish effective connections with the right users, and greatly reduce the cost for consumers to collect electronic product information and the marketing cost of enterprises. Therefore, how to identify opinion leaders of electronic products and evaluate their competence is of great significance.

\section{MATERIALS AND METHODS}

An opinion leader refers to a person who often provides information and exerts influence on other audiences in interpersonal communication network, and plays two important roles of "information intermediary" and "influence" [1-2].Previous studies mainly from three dimensions of activity, centricity, and intermediary index system of competence of opinion leaders to build [3-4], activity reflects the opinion leaders in the process of information dissemination activity, centricity reflect the opinion leaders information production capacity and production quality, the intermediary reflects the opinion leader ability to filter information and control connection.
Table 1 Competency evaluation index system of opinion leaders of electronic products.

\begin{tabular}{|c|c|c|}
\hline Dimensions & Indicators & Meaning \\
\hline \multirow{3}{*}{$\begin{array}{l}\text { Activity } \\
\text { (A) }\end{array}$} & Attention al & $\begin{array}{l}\text { Pay attention to the number of electronic } \\
\text { product information release subjects. }\end{array}$ \\
\hline & $\begin{array}{c}\text { Sharing } \\
\text { Frequency a2 }\end{array}$ & $\begin{array}{l}\text { How often you actively share } \\
\text { information about your electronic } \\
\text { products. }\end{array}$ \\
\hline & $\begin{array}{c}\text { Recovery } \\
\text { Frequency a3 }\end{array}$ & $\begin{array}{l}\text { How often you answer questions and } \\
\text { puzzles about electronics. }\end{array}$ \\
\hline \multirow{4}{*}{$\begin{array}{l}\text { Centrality } \\
\text { (B) }\end{array}$} & Influence b1 & $\begin{array}{l}\text { Audience size and electronic product } \\
\text { information diffusion speed. }\end{array}$ \\
\hline & Professional b2 & $\begin{array}{l}\text { The degree of professionalism of the } \\
\text { electronic product information } \\
\text { published. }\end{array}$ \\
\hline & Innovative b3 & $\begin{array}{l}\text { Originality and differentiation of shared } \\
\text { electronic product information. }\end{array}$ \\
\hline & Focus b4 & $\begin{array}{l}\text { The percentage of tweets, palindromes, } \\
\text { and reposts of specific product } \\
\text { information. }\end{array}$ \\
\hline \multirow{2}{*}{$\begin{array}{c}\text { Intermediar } \\
\mathrm{y}(\mathrm{C})\end{array}$} & $\begin{array}{l}\text { Control } \\
\text { connection } \\
\text { capability c1 }\end{array}$ & $\begin{array}{l}\text { The ability to control and connect with } \\
\text { an audience. }\end{array}$ \\
\hline & $\begin{array}{l}\text { Information } \\
\text { filtering } \\
\text { capability c2 }\end{array}$ & $\begin{array}{l}\text { The ability to filter information from } \\
\text { electronic products. }\end{array}$ \\
\hline
\end{tabular}

The number of attention can reflect the extensive information source channels of opinion leaders to some extent. The initiative of opinion leaders to share and answer questions and information related to electronic products represents the willingness of opinion leaders to play the role. The more professional the opinion leaders are, and the more they focus on electronic products, the

$\mathrm{a}^{*}$ Corresponding author: ${ }^{\mathrm{a}} \mathrm{zshitwh} @ 163 . c o m$
be-mail: 20s030225@stu.hit.edu.cn 
higher the quality of information produced, the stronger the originality and influence, and the better the effect of electronic product information dissemination. Opinion leaders are at the core of many communication paths and can influence groups through information filtering and connection and other intermediary capabilities [5]. This paper attempts to establish a competency evaluation index system for opinion leaders of electronic products based on previous studies on the industry and characteristics of electronic products, as shown in Table 1.

The analysis method of decision laboratory (DEMATEL) reveals the complex relationship and intensity among influencing factors by establishing Influence Network Relation Map(INRM). The DEMATEL-Basd Analytic Network Process (DANP) takes DEMATEL's total influence matrix as the unweighted super matrix of ANP to process, which eliminates the need to collect the questionnaire again. The weight of each evaluation index can be calculated by the DANP technology. This paper uses DEMATEL-ANP technique to carry out empirical research.

Step1: Obtain the initial scoring matrix. Nine experts engaged in marketing research or work were invited to rate the degree of influence among the nine evaluation indicators of competence factors from 0 to 6 , which in turn represented: no influence, little influence, little influence, average influence, large influence, great influence, and complete influence. The initial score matrix M (Table2) of the degree of interaction among key competency features was finally obtained after repeated modification according to their feedback.

$$
M=\left(\begin{array}{cccc}
0 & m_{l 2} & \cdots & m_{l n} \\
m_{21} & 0 & \cdots & m_{2 n} \\
\vdots & \vdots & & \vdots \\
m_{n 1} & m_{n 2} & \cdots & 0
\end{array}\right)=\left(m_{i j}\right)_{n \times n}
$$

Table 2 The initial score matrix M.

\begin{tabular}{|c|c|c|c|c|c|c|c|c|c|}
\hline & a1 & a2 & a3 & b1 & b2 & b3 & b4 & c1 & c2 \\
\hline a1 & 0.000 & 4.778 & 4.222 & 3.889 & 4.333 & 3.444 & 4.667 & 3.556 & 5.222 \\
\hline a2 & 4.889 & 0.000 & 5.111 & 5.222 & 3.889 & 3.889 & 4.444 & 5.111 & 3.556 \\
\hline a3 & 4.333 & 5.000 & 0.000 & 4.556 & 4.000 & 4.111 & 4.222 & 4.333 & 4.222 \\
\hline b1 & 5.000 & 5.111 & 4.778 & 0.000 & 4.222 & 4.111 & 4.778 & 5.222 & 5.111 \\
\hline b2 & 4.889 & 4.333 & 4.111 & 5.111 & 0.000 & 4.667 & 5.000 & 5.111 & 5.222 \\
\hline b3 & 4.556 & 4.778 & 4.444 & 4.889 & 5.222 & 0.000 & 4.667 & 4.556 & 4.444 \\
\hline b4 & 4.556 & 4.778 & 4.889 & 5.000 & 4.444 & 4.778 & 0.000 & 4.000 & 5.000 \\
\hline c1 & 3.556 & 5.000 & 4.444 & 4.667 & 4.889 & 4.000 & 4.444 & 0.000 & 3.556 \\
\hline c2 & 3.556 & 5.000 & 5.000 & 5.111 & 5.000 & 3.889 & 5.111 & 5.222 & 0.000 \\
\hline
\end{tabular}

Step2: Obtain the direct influence matrix. Through Equation(2) and Equation(3), the initial score matrix $M$ is standardized, so that the direct influence matrix $\mathrm{X}$ meets the requirement that the sum of one row or one column is at least 1 .

$$
\begin{aligned}
& s=\min \left\{1 / \max _{i} \sum_{j}^{n} m_{i j}, 1 / \max _{j} \sum_{i=1}^{n} m_{i j}\right\} \\
& \mathrm{X}=s \mathrm{M}
\end{aligned}
$$

Step 3: Use Equation(4) to get the total influence matrix $T_{c}$.

$$
T_{c}=\mathrm{X}+\mathrm{X}^{2}+\mathrm{X}^{3}+\cdots+\mathrm{X}^{\mathrm{n}}=\mathrm{X}(\mathrm{I}-\mathrm{X})^{-1}
$$

Table 3 The total influence matrix $T_{c}$.

\begin{tabular}{|c|c|c|c|c|c|c|c|c|c|}
\hline & a1 & a2 & a3 & b1 & b2 & b3 & b4 & c1 & c2 \\
\hline a1 & 1.5981 & 1.8463 & 1.7656 & 1.8151 & 1.7200 & 1.5795 & 1.7845 & 1.7559 & 1.7544 \\
\hline a2 & 1.7878 & 1.8210 & 1.8643 & 1.9253 & 1.7890 & 1.6611 & 1.8604 & 1.8684 & 1.7987 \\
\hline a3 & 1.7243 & 1.8787 & 1.6938 & 1.8561 & 1.7389 & 1.6171 & 1.8016 & 1.7986 & 1.7591 \\
\hline b1 & 1.8838 & 2.0399 & 1.9560 & 1.9085 & 1.8919 & 1.7540 & 1.9666 & 1.9696 & 1.9270 \\
\hline b2 & 1.8907 & 2.0338 & 1.9516 & 2.0350 & 1.8034 & 1.7744 & 1.9810 & 1.9770 & 1.9394 \\
\hline b3 & 1.8480 & 2.0030 & 1.9203 & 1.9912 & 1.8849 & 1.6330 & 1.9358 & 1.9276 & 1.8860 \\
\hline b4 & 1.8431 & 1.9981 & 1.9248 & 1.9884 & 1.8640 & 1.7381 & 1.8233 & 1.9112 & 1.8925 \\
\hline c1 & 1.7021 & 1.8713 & 1.7896 & 1.8517 & 1.7505 & 1.6093 & 1.7993 & 1.6916 & 1.7387 \\
\hline c2 & 1.8406 & 2.0226 & 1.9463 & 2.0109 & 1.8939 & 1.7374 & 1.9590 & 1.9560 & 1.7964 \\
\hline
\end{tabular}

Step 4: Build the INRM diagram. Add each row and each column of the total influence matrix $T_{c}=\left[T_{i j}\right]$ to get the sum of vectors of all rows and columns, as shown in Equations (5) and (6). The INRM diagrams within the dimension and between dimensions are shown in Figure.1 from (a) to (d).

$$
\begin{aligned}
& \left.k=\left[k_{i}\right]_{n \times 1}=\sum_{j=1}^{n} t_{i j}\right]_{n \times 1}=\left(k_{1}, \cdots k_{i} \cdots, k_{n}\right) \\
& \left.d=\left[d_{j}\right]_{1 \times n}=\sum_{i=1}^{n} t_{i j}\right]_{1 \times n}=\left(d_{1}, \cdots d_{i} \cdots, d_{n}\right)
\end{aligned}
$$

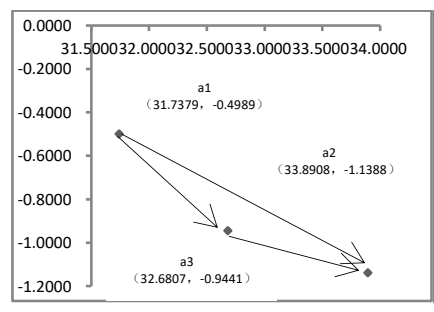

(a) Activity dimension

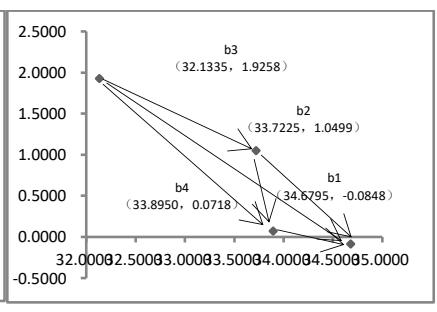

(b) Centrality dimension 


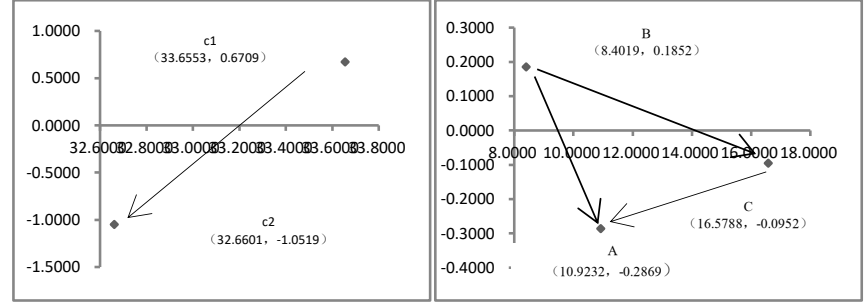

(c) Intermediary dimension (d) Total

Figure.1 Each dimension and total INRM diagram.

Table 4 The influence degree value of each competency factor.

\begin{tabular}{|c|c|c|c|c|}
\hline & $k_{i}$ & $d_{i}$ & $k_{i}+d_{i}$ & $k_{i}-d_{i}$ \\
\hline $\mathrm{A}$ & 5.3182 & 5.6051 & 10.9232 & -0.2869 \\
\hline $\mathrm{B}$ & 4.2936 & 4.1084 & 8.4019 & 0.1852 \\
\hline $\mathrm{C}$ & 8.2418 & 8.3370 & 16.5788 & -0.0952 \\
\hline
\end{tabular}

Among them, $k_{i}$ on behalf of the competency elements $i$ ( $i$ include A, B, C three competency elements) impact on other competency elements total value, $d_{i}$ representative competency elements $i$ affected by other competency elements total value, $k_{i}+d_{i}$ representative competency $i$ have all influence factors of value, on behalf of the center of the competence elements, $k_{i}-d_{i}$ representative competency elements $i$ the net impact of value, because of the competence elements are represented.

Step 5: Normalize the matrices $T_{c}$ and $T_{D}$ to obtain the matrices $T_{c}{ }^{a}$ and $T_{D}{ }^{a}$. The total influence matrix $T_{c}$ of element angles and the total influence matrix $T_{D}$ of dimension angles are obtained from the previous sections. Note that the value of $T_{D}$ is the average of the corresponding dimension $T_{c}$. The normalization process of matrix $T_{c}$ is shown in Equations (7) - (15).

$$
\begin{gathered}
C_{i}=\sum_{j=1}^{n} T^{i j}, j=1,2, \cdots, n \\
T_{c}^{a^{i j}}=T_{c}^{i j} / C_{i}, \quad i=1,2, \ldots, n \\
D_{1} c_{11} \\
c_{12} \\
\vdots \\
\vdots
\end{gathered}
$$

$$
\begin{aligned}
& d_{i}=\sum_{j=1}^{n} t_{D}^{i j}, i=1,2, \cdots, n \\
& t_{D}^{i j}=\left(\sum_{i=1}^{p} \sum_{j=1}^{q} T_{i j}\right) /(p \times q), i=1,2, \cdots, p ; j=1,2, \cdots, q \\
& t_{D}^{a^{i j}}=t_{D}^{i j} / d_{i}, i=1,2, \cdots, n \\
& T_{D}=\left[\begin{array}{ccccc}
t_{D}^{11} & \cdots & t_{D}^{1 j} & \cdots & t_{D}^{1 m} \\
\vdots & & \vdots & & \vdots \\
t_{D}^{i 1} & \cdots & t_{D}^{i j} & \cdots & t_{D}^{i m} \\
\vdots & & \vdots & & \vdots \\
t_{D}^{m 1} & \cdots & t_{D}^{m j} & \cdots & t_{D}^{m m}
\end{array}\right]_{m \times m}
\end{aligned}
$$

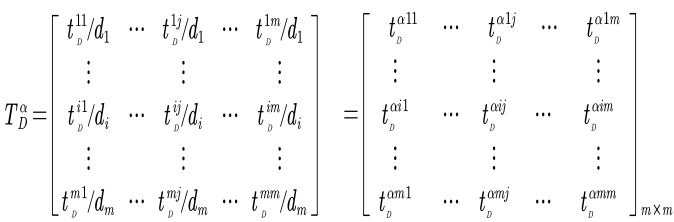

Step 6: According to Equation (16), the unweighted supermatrix $W$ is obtained.

$$
W=\left(T_{c}^{\alpha}\right)^{-1}
$$

Step 7: The normalized super-matrix $W^{\alpha}$ is obtained by using Equation (17).

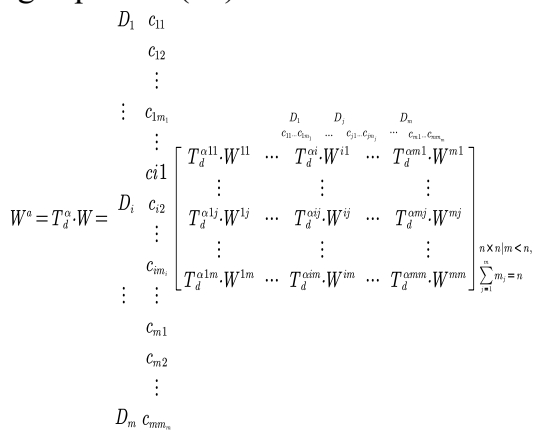

Step 8: Use Equations (18) to limit processing of the standardized super matrix $W^{a}$ to obtain the steady-state matrix.

$$
\lim _{z \rightarrow \infty}\left(W^{\alpha}\right)^{z}
$$

\section{RESULTS \& DISCUSSION}

Can be seen from Figure.2, in the heart (B), in turn, affects the activity in the intermediary (C) and (A), it shows that electronic products competence elements of opinion leaders need most is centricity, that is to say, the quality of the production of electronic products information by opinion leaders and effect directly affect the opinion leader in electronic products in the process of information transmission control, connect the ability of the masses, 
opinion leader specialization and concentration can improve the filtering ability of opinion leaders; the influence and professionalism of opinion leaders make them recognized and respected, which makes them more active on the Internet. The ability of opinion leaders to filter information and connect with the masses encourages them to understand and pay attention to more productrelated information, which also makes them more eager to share and more active on social platforms.

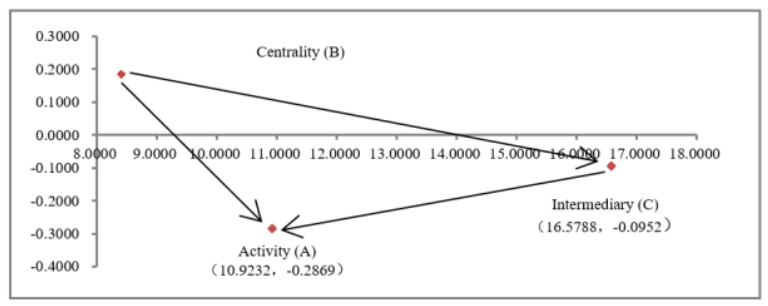

Figure.2 The INRM diagram between dimensions.

Table 6 Summary of weights in the dimension of opinion leaders of electronic products and the global weights of each index.

\begin{tabular}{|c|c|c|}
\hline Dimensions/Indicators & $\begin{array}{c}\text { Weight within } \\
\text { dimension }\end{array}$ & $\begin{array}{c}\text { Global } \\
\text { weight }\end{array}$ \\
\hline Activity (A) & 0.3361 & \\
\hline Attention a1 & 0.3193 & 0.1073 \\
\hline Sharing Frequency a2 & 0.3472 & 0.1167 \\
\hline Recovery Frequency a3 & 0.3335 & 0.1121 \\
\hline Centrality (B) & 0.3305 & \\
\hline Influence b1 & 0.2644 & 0.0874 \\
\hline Professional b2 & 0.2487 & 0.0822 \\
\hline Innovative b3 & 0.2297 & 0.0759 \\
\hline Focus b4 & 0.2572 & 0.0850 \\
\hline Intermediary (C) & 0.3335 & \\
\hline Control Connection Capability c1 & 0.5055 & 0.1686 \\
\hline Information Filtering Capability & 0.4945 & 0.1649 \\
\hline
\end{tabular}

According to Table 6, the weights of activity, centrality and intermediation are respectively $33.61 \%, 33.05 \%$ and $33.35 \%$, with little difference and relatively uniform distribution. The more active the opinion leader is, the more 'opinions' he puts forward directly to the audience. Second, it is necessary to have a strong intermediary ability. Good opinion leaders need to extract and summarize the complex information of electronic products, and have enough ability to control and connect the audience, so as to make electronic product information dissemination more effective and powerful. Electronics opinion leaders in the production of information quality and communication effect, namely the opinion leaders to produce 'opinion' more professional, more easily accepted by the audience and convincing, more focus on electronic products, the production information is more targeted, opinion leaders personal view would be more objective and more convincing, the flow of opinion leaders has great value.

\section{CONCLUSIONS}

This paper discusses the identification and analysis of the competency elements of opinion leaders of electronic products, and quantifies the weights of these elements and their evaluation indexes. According to the research results of this paper, it can help enterprises to identify opinion leaders of electronic products and provide empirical support to make the process of electronic product information transmission from enterprises to consumers more direct and effective, and provide scientific decisionmaking basis for marketers in the electronic product industry to carry out marketing activities.

The conclusions and contributions of this study are summarized as follows: (1) Determine the key competency elements of opinion leaders of electronic products and construct an evaluation index system. (2) The interaction between the various elements of the competence of opinion leaders of electronic products and their evaluation indicators is discussed. (3) The weights of each dimension of competency elements and its evaluation indexes are obtained.

There are still some shortcomings in this study. First, the reconstruction of the index system based on the current situation of the electronic product industry is subjective to a certain extent; second, the collection of expert questionnaires is limited to marketers and marketing researchers, and the questionnaire collection is not conducted from the perspective of consumers and opinion leaders.

\section{REFERENCES}

1. Lazarsfeld P F, Berelson B, Gaudet H. The People's Choice[M]. Oxford, England: Duell, Sloan \& Pearce, 1944.

2. Rogers E M. Diffusion of Inovations[M]. The 5th Edition. Free Press, 2003.

3. Yanyan Li, Shaoqian Ma, Yonghe Zhang, Ronghuai Huang, Kinshuk. An improved mix framework for opinion leader identification in online learning communities[J]. Knowledge-Based Systems,2013,43.

4. Margarita E. Romero-Rodríguez, M. Carolina Rodríguez-Donate, M. Carmen Hernández-García, M. Gracia Rodríguez-Brito. Influence of opinion leadership identification criteria: The purchase of smartphones[J]. Journal of Retailing and Consumer Services,2020,56(C).

5. Freeman L C. A set of measures of centrality based on betweenness. Sociometry, 1977, (1):35-41. 